\title{
Delays in Neurological Drug Development in Japan
}

\author{
Rumiko Shimazawa and Masayuki Ikeda
}

\begin{abstract}
Objective The lag in the approval and development of neurological drugs between Japan and other countries has been a major issue for patients with neurological diseases. The objective of this study was to analyze the factors contributing to the delay in the launching of neurological drugs in Japan.

Methods We analyzed data from Japan and the US for the approval of 36 standard neurological drugs and examined the potential factors that may cause the delay of their launch.

Results Of the 36 standard neurological drugs, all of which were approved in the US, only 21 were introduced in Japan from June 1999 to April 2010, whereas the other 15, whose indications were Alzheimer disease, epilepsy, migraine, multiple sclerosis, and Parkinson disease, remained unapproved. The US led Japan in the number of introductions (20 versus 1), with introductions in Japan occurring at a median of 87 months after introductions in the US. Japan's review time of new drug applications (23 months) could not explain this lag. In 15 of the 21 approved drugs, the application data package included overseas data. The mean review time of these 15 drugs was significantly shorter than that of the other 6 drugs without overseas data. The maximum daily doses of 7 of the drugs were higher in the US than in Japan.

Conclusion These results show that there is still a large gap between Japan and the US with regard to access to standard neurological drugs, despite several important reforms in the Japanese drug approval system.
\end{abstract}

Key words: drug approval, clinical trials, food and drug administration, International Conference on Harmonisation of Technical Requirements for Registration of Pharmaceuticals for Human Use (ICH)

(Intern Med 50: 1565-1568, 2011)

(DOI: 10.2169/internalmedicine.50.5061)

\section{Introduction}

There is still a large gap between Japan and other developed countries with regard to access to new drugs, despite several important reforms in the Japanese drug approval system $(1,2)$, including implementation of the International Conference on Harmonisation of Technical Requirements for Registration of Pharmaceuticals for Human Use (ICH) good clinical practice (GCP), establishment of the new regulatory authority in 1997, and implementation of Ethnic Factors in the Acceptability of Foreign Clinical Data (ICH E5) guidelines in 1998. A study of the top 100 drugs by sales in 2004 shows a 2.5-year gap between the launch dates in Japan and those in the US (3). "Drug lag" $(4,5)$ is the term coined to describe this situation. Of the 398 new chemical entities that were approved in either the US, European Union (EU), or Japan between 1999 and 2007, 325 (82\%) and 314 (79\%) were approved in the US and EU, respectively, whereas only $220(55 \%)$ were approved in Japan (5). The longest delays in approval were for drugs of the central nervous system (CNS) $(4,5)$. Japan lags behind the UK in neurological drug approvals with a median delay of 65 months (6).

Because of this lag, Japanese patients with neurological diseases cannot gain access to these drugs as early as patients in other developed nations. Drug lag may not only prevent Japanese patients from receiving certain treatments available in other regions but also delay the progress of clinical research in Japan. The purpose of this study was to analyze the factors contributing to the drug lag of neurological drugs in Japan by comparing Japanese approval data with those of the US.

\section{Materials and Methods}

We analyzed Japanese and US data for the approval of 
Table 1. Japanese and US Data Regarding the Approval of Neurological Drugs

\begin{tabular}{|c|c|c|c|c|c|c|c|c|c|}
\hline \multirow{2}{*}{$\begin{array}{l}\text { Generic name } \\
\text { (proprietary) }\end{array}$} & \multirow[t]{2}{*}{ Indication } & \multirow{2}{*}{$\begin{array}{c}\text { Application } \\
\text { Date } \\
\text { Japan }\end{array}$} & \multicolumn{2}{|c|}{ Approval Date } & \multirow{2}{*}{$\begin{array}{c}\text { Review } \\
\text { Time } \\
\text { (Months) }\end{array}$} & \multirow{2}{*}{$\begin{array}{c}\text { Lag } \\
\text { (Months) }\end{array}$} & \multirow{2}{*}{$\begin{array}{c}\text { Overseas } \\
\text { Data }\end{array}$} & \multicolumn{2}{|c|}{ Maximum Dose/day (*1) } \\
\hline & & & Japan & US & & & & Japan & US \\
\hline Donepezil & Alzheimer disease & Jul-98 & Oct-99 & Nov-96 & 14 & 34 & Yes & 10 & 10 \\
\hline Galantamine & Alzheimer disease & & & Feb-01 & & & & & \\
\hline Memantine & Alzheimer disease & & & Oct-03 & & & & & \\
\hline Rivastigmine & Alzheimer disease & & & Apr-00 & & & & & \\
\hline Clobazam & Epilepsy & Mar-97 & Mar-00 & Feb-79 & 36 & 253 & No & 40 & 60 \\
\hline Fosphenytoin & Epilepsy & & & Aug-96 & & & & & \\
\hline Gabapentin & Epilepsy & Apr-04 & Jul-06 & Dec-93 & 27 & 151 & No & 2400 & 4800 \\
\hline Lamotrigine & Epilepsy & Dec-05 & Oct-08 & Dec-94 & 34 & 166 & Yes & 400 & 500 \\
\hline Levetiracetam & Epilepsy & & & Nov-99 & & & & & \\
\hline Oxcarbazepine & Epilepsy & & & Jan-00 & & & & & \\
\hline Rufinamide & Epilepsy & & & Nov-08 & & & & & \\
\hline Topiramate & Epilepsy & Jul-04 & Jul-07 & Dec-96 & 36 & 127 & No & $600(* 2)$ & *3 \\
\hline Vigabatrin & Epilepsy & & & Aug-09 & & & & & \\
\hline Clopidogrel & Ischemic stroke & Feb-04 & Jan-06 & Nov-97 & 23 & 98 & No & 75 & 75 \\
\hline Almotriptan & Migraine & & & May-01 & & & & & \\
\hline Eletriptan & Migraine & Jun-00 & Apr-02 & Dec- 02 & 21 & -9 & Yes & 40 & 80 \\
\hline Frovatriptan & Migraine & & & Nov-01 & & & & & \\
\hline Naratriptan & Migraine & Apr-06 & Jan- 08 & Feb-98 & 21 & 120 & Yes & 5 & 5 \\
\hline Rizatriptan & Migraine & Nov-01 & Jul-03 & Jun-98 & 20 & 61 & Yes & 20 & 20 \\
\hline Sumatriptan & Migraine & May-01 & Apr-03 & Aug-97 & 23 & 68 & Yes & 40 & 40 \\
\hline Sumatriptan succinate & Migraine & Aug-00 & Jun-01 & Jun-95 & 11 & 73 & Yes & 200 & 300 \\
\hline Zolmitriptan & Migraine & Mar-00 & Jun-01 & Nov-97 & 15 & 43 & Yes & 10 & 10 \\
\hline Glatiramer acetate & Multiple sclerosis & & & Dec-87 & & & & & \\
\hline Interferon beta-1a (Avonex) & Multiple sclerosis & Jun-03 & Jul-06 & May-96 & 37 & 122 & Yes & $30 \mu \mathrm{g}(* 4)$ & $30 \mu \mathrm{g}(* 4)$ \\
\hline Interferon beta-1a (Rebif) & Multiple sclerosis & & & Mar-02 & & & & & \\
\hline Interferon beta- $1 \mathrm{~b}$ & Multiple sclerosis & Sep-99 & Sep-00 & Jul-93 & 12 & 86 & Yes & $250 \mu \mathrm{g}(* 5)$ & $250 \mu \mathrm{g}(* 5)$ \\
\hline Natalizumab & Multiple sclerosis & & & Nov-04 & & & & & \\
\hline Pregabalin & Neuropathic Pain & May-08 & Apr-10 & Dec-04 & 23 & 64 & Yes & 3 & 3 \\
\hline Cabergoline & Parkinson disease & NA & Jun-99 & Dec-96 & & 30 & No & 4.5 & 4.5 \\
\hline Entacapone & Parkinson disease & Apr-05 & Jan-07 & Oct-99 & 21 & 87 & Yes & 1600 & 2000 \\
\hline Pramipexole & Parkinson disease & Dec-01 & Oct- 03 & Jul-97 & 22 & 76 & Yes & 15 & 15 \\
\hline Rasagiline & Parkinson disease & & & May-06 & & & & & \\
\hline Ropinirole & Parkinson disease & Dec-02 & Oct-06 & Sep-97 & 46 & 109 & No & 15 & 24 \\
\hline Rotigotine & Parkinson disease & & & May-07 & & & & & \\
\hline Alglucosidase alfa & Pompe disease & Apr-05 & Apr-07 & Apr-06 & 24 & 12 & Yes & $20 \mathrm{mg} / \mathrm{kg}(* 6)$ & $20 \mathrm{mg} / \mathrm{kg}(* 6)$ \\
\hline Zinc acetate & Wilson disease & May-06 & Jan- 08 & Jan-97 & 21 & 132 & Yes & 250 & 250 \\
\hline
\end{tabular}

*1 Doses are in $\mathrm{mg}$ except if otherwise specified.

*2 Only adjunctive therapies for epilepsy are approved in Japan.

*3 The US label states, "The usual daily dose is 200-400 mg in two divided doses." without description of the maximum dose.

*4 Administered by intramuscular injection once a week

*5 Administered subcutaneously every other day

*6 Administered once every 2 weeks as an intravenous infusion

standard neurological drugs recommended in the guidelines (http://www.guideline.gov/). Japanese data were obtained from the website of the Japan Pharmaceutical Information Center (JAPIC), from the section on new drug approval (http://www.shinsahoukokusho.jp/), which included a data set of all new molecular entities and biologics approved in Japan between June 1999 and April 2010. US data were obtained from Drugs@FDA (http://www.accessdata.fda.gov/ Scripts/cder/DrugsatFDA/index.cfm).

Approval delay was defined as the difference between the date of approval in Japan and that in the US. Japan's review time was defined as the time between the date of application for approval and the actual date of approval. We used the Mann-Whitney $U$ test to compare the data between the two groups. A p value less than 0.05 was regarded as statistically significant.

\section{Results}

Table 1 shows the results of our analysis. Of the 36 standard neurological drugs, only 21 were introduced in Japan from June 1999 to April 2010. The therapeutic indications of the 15 unapproved drugs were Alzheimer disease, epilepsy, migraine, multiple sclerosis, and Parkinson disease. To investigate the effect of the time of development in the US on the approval date in Japan, we compared the date of approval in the US between the approved 21and unapproved 15 drugs in Japan; however, we found no significant differ- 
Table 2. Effects of Overseas Data on the Lag and Review Time of Approved Neurological Drugs

\begin{tabular}{lccc}
\hline & \multicolumn{2}{c}{ Overseas Data } & \multirow{2}{*}{ p value } \\
& Yes $(\mathrm{n}=15)$ & No $(\mathrm{n}=6)$ & \\
\hline Review Time & $21(7)$ & $34(9)$ & $<0.02$ \\
Lag & $76(46)$ & $128(75)$ & NS \\
\hline
\end{tabular}

Data represent mean (SD).

Statistical analysis was performed by means of the Mann-Whitney $U$ test.

Table 3. Effects of Maximum Doses on the Lag and Review Time of Approved Neurological Drugs

\begin{tabular}{lccc}
\hline & \multicolumn{2}{c}{ Maximum Dose } & p value \\
& Same $(\mathrm{n}=14)$ & Lower $(\mathrm{n}=7)$ & \\
\hline Review Time & $22(7)$ & $28(12)$ & NS \\
Lag & $77(39)$ & $119(82)$ & NS \\
\hline
\end{tabular}

Data represent mean $(\mathrm{SD})$.

Statistical analysis was performed by means of the Mann-Whitney $U$ test.

ence $(\mathrm{p}>0.05)$.

The median review time (from approval application to final approval) of the 21 drugs approved in Japan was 23 months. Twenty drugs were approved in Japan after their approval in the US, except for eletriptan, which was approved in Japan 9 months before its approval in the US. The delay of approval in Japan after approval in the US was 87 months (median time).

Fifteen of the 21 drugs included overseas data in their application package. Between these 15 drugs and the other 6 drugs without overseas data, a significant difference was noted in the review time $(\mathrm{p}<0.02$; Table 2$)$. The mean delay in approval in Japan after approval in the US was longer in the 15 drugs with overseas data than in those without, but the difference was not statistically significant.

Of the 21 drugs approved in Japan, the maximum daily doses of 7 drugs (clobazam, gabapentin, lamotrigine, eletriptan, sumatriptan succinate, entacapone, and ropinirole) were higher in the US than in Japan. Between these 7 drugs and the other 14 drugs with the same maximum daily dose as that in the US, no significant difference was noted in either the review time or delay in the approval in Japan after approval in the US (Table 3).

The 21 drugs approved in Japan fell into four categories with the two variables (overseas data and maximum dose); drugs with overseas data and with the same maximum dose $(n=11)$, those with overseas data but with lower maximum doses $(n=4)$, those without overseas data and with the same maximum dose $(n=3)$, and those without overseas data but with lower maximum doses $(n=3)$. Table 4 shows the lag and Table 5 shows the review time in these four categories. No significant difference was noted in either the lag or review time.
Table 4. Effects of Maximum Doses and Overseas Data on the Lag of Approved Neurological Drugs

\begin{tabular}{ccccc}
\hline & & \multicolumn{2}{c}{ Maximum Dose } & \multirow{2}{*}{ p value } \\
& & Same & Lower & \\
\hline \multirow{2}{*}{ Overseas Data } & Yes & $65(35)$ & $79(72)$ & NS \\
& No & $85(50)$ & $171(74)$ & NS \\
p value & & NS & NS & \\
\hline
\end{tabular}

Data represent mean (SD).

Statistical analysis was performed by means of Mann-Whitney $U$ test.

Table 5. Effects of Maximum Doses and Overseas Data on the Review Time of Approved Neurological Drugs

\begin{tabular}{ccccc}
\hline & & \multicolumn{2}{c}{ Maximum Dose } & \multirow{2}{*}{ p value } \\
& & Same & Lower & \\
\hline \multirow{2}{*}{ Overseas Data } & Yes & $21(7)$ & $22(9)$ & NS \\
& No & $30(9)$ & $36(10)$ & NS \\
p value & & NS & NS & \\
\hline
\end{tabular}

Data represent mean (SD).

Statistical analysis was performed by means of Mann-Whitney $U$ test.

\section{Discussion}

Our analysis, which focused on the introduction of neurological drugs in Japan, showed that only 21 of the 36 standard drugs were approved, with delays of 87 months after their approval in the US. The launch delay includes the delay in development (i.e., up to approval application) as well as the delay in review. The median review time of 23 months as determined in our study is longer than that of 10 months in the Food and Drug Administration (7). The 13month difference in review time, however, cannot explain the overall 87 month delay in Japan after approval in the US. Although we could not precisely identify the development time, the above-mentioned data show that most of the delay is presumably due to delays in development and not review. The median clinical development time, defined as the time from initial clinical trial plan notification to submission of new drug application, was 61.2 and 58.7 months in the US and Japan, respectively, for drugs approved between 1998 and 2007 in Japan (7). Thus, a substantial part of the submission delay is assumed to be caused by the delay in initiation of clinical development in Japan and not clinical development itself.

A development strategy $(8,9)$ based on the ICH-E5 guidelines exists to minimize the duplication of clinical data. After the implementation of the guidelines, many new drug applications that utilized overseas data were approved in Japan. The shorter review time and lag in the cases with overseas data in the present study, although the latter was not statistically significant, suggest that the simultaneous development of drugs on a global scale effectively reduces the delay. Because of the following problems, however, this goal seems difficult to achieve. The difference in the preva- 
lence of some neurological disorders, e.g., multiple sclerosis, between Japan and the US hinders the recruitment sufficient numbers of patients for clinical trials in Japan. Social barriers, e.g., language problems among Japanese participants in multinational trials and the high cost and low performance of clinical trials in Japan (5), may have a significant effect on drug development in Japan.

The lower maximum daily doses in Japan than those in the US, as observed in the present and other studies $(10,11)$, is another hindrance to the development of neurological drugs in Japan. Although we found no statistically significant effect of the maximum doses on the lag and review time in the present study, differences in doses between the two regions often result in difficulties in extrapolating data from one region to the other. Although the difference in doses $(10,11)$ could affect clinical development time in Japan, no study provides direct evidence for such effect. First, we could not precisely identify the development time, since the starting date of clinical development is confidential. Second, even if we knew the date, some strategies, e.g. the bridging study $(8,9)$, to minimize the duplication of clinical data, may have reduced the effect of the difference in doses on clinical development time in Japan.

In contrast to these 21 drugs already approved in Japan, $15(42 \%)$ of 36 drugs are approved in the US but not in Japan. This figure, the so-called absolute drug lag, is similar to that reported by Tsuji and Tsutani (5). They showed that $27(47 \%)$ of 58 drugs approved in either the US or UK for neurological or psychiatric diseases were not available in Japan in 2007. In conclusion, the data presented in this study confirm that Japan's drug lag in the case of neurological drugs is quite substantial and underscore the necessity for viable approaches to enhance access to novel treatments for patients with neurological diseases.
The authors state that they have no Conflict of Interest (COI).

\section{References}

1. Fujiwara Y. MD reviewers' role in the new anticancer drug approval process in the newly established Japanese regulatory agency, PMDEC (Pharmaceuticals and Medical Devices Evaluation Center). Jpn J Clin Oncol 28: 653-656, 1998.

2. Fujiwara Y, Kobayashi K. Oncology drug clinical development and approval in Japan: the role of the pharmaceuticals and medical devices evaluation center (PMDEC). Crit Rev Oncol Hematol 42: 145-155, 2002.

3. Fukuhara H. Period between world first launch and country launch. OPIR Research Paper No. 31: 2006 (in Japanese)..

4. Hirai Y, Kinoshita H, Kusama M, Yasuda K, Sugiyama Y, Ono S. Delays in new drug applications in Japan and industrial R \& D strategies. Clin Pharmacol Ther 87: 212-218, 2010.

5. Tsuji K, Tsutani K. Approval of new drugs 1999-2007: comparison of the US, the EU and Japan situations. J Clin Pharmacy Therapy 35: 289-301, 2010.

6. Shimazawa R, Ikeda M. Japan lags behind the UK in neurological drug approvals. Br J Clin Pharmacol 71: 473-475, 2011.

7. Yasuda K, Ono S. New drug development times in Japan. Time of clinical development and approval. OPIR Research Paper No. 42: 2008 (in Japanese).

8. Shimazawa R, Ando Y, Hidaka S, Saito K, Toyoshima S, Kobayashi F. Development of triptans in Japan: Bridging strategy based on the ICH-E5 guideline. J Health Sci 52: 443-449, 2006.

9. Uyama Y, Shibata T, Nagai N, Hanaoka H, Toyoshima S, Mori K. Successful bridging strategy based on ICH E5 guideline for drugs approved in Japan. Clin Pharmacol Ther 78: 102-113, 2005.

10. Arnold FL, Kusama M, Ono S. Exploring differences in drug doses between Japan and Western countries. Clin Pharmacol Ther 87: 714-720, 2010.

11. Malinowski HJ, Westelinck A, Sato J, Ong T. Same drug, different dosing: differences in dosing for drugs approved in the United States, Europe, and Japan. J Clin Pharmacol 48: 900-908, 2008.

(C) 2011 The Japanese Society of Internal Medicine http://www.naika.or.jp/imindex.html 